\title{
Application of Dual-Energy K-Edge Subtraction Imaging to Assessment of Heat Treatments in Al-Cu Alloys
}

\author{
Hiroyuki Toda ${ }^{1, * 1}$, Kazuyuki Shimizu ${ }^{1, * 2}$, Kentaro Uesugi ${ }^{2}$, \\ Yoshio Suzuki ${ }^{2}$ and Masakazu Kobayashi ${ }^{1}$ \\ ${ }^{1}$ Department of Mechanical Engineering, Toyohashi University of Technology, Toyohashi 441-8580, Japan \\ ${ }^{2}$ Japan Synchrotron Radiation Research Institute, Sayo-gun, Hyogo 679-5198, Japan
}

\begin{abstract}
Dual-energy K-edge subtraction imaging technique has been employed to analyze the spatial distribution of copper and its change in threedimensions quantitatively during a solution treatment. In order to realize it, some preliminary investigations on the verification and assurance of accuracy and repeatability have been performed. Inhomogeneous $\mathrm{Cu}$ concentration distribution is revealed even after the solution treatment for a sufficiently long period of time at a high temperature in an $\mathrm{Al}-\mathrm{Cu}$ alloy. The present technique has a unique potential to realize four-dimensional chemical-concentration mapping. [doi:10.2320/matertrans.L-M2010819]
\end{abstract}

(Received April 16, 2010; Accepted July 13, 2010; Published October 14, 2010)

Keywords: solution heat treatment, aluminum-copper alloy, X-ray tomography, $K$-edge subtraction imaging, chemical concentration mapping

\section{Introduction}

Although a few experimental techniques, such as serial sectioning technique combined with SEM-EBSP and atomprobe tomography, allow the $3 \mathrm{D}$ reconstruction of chemical concentration, the extension to $4 \mathrm{D}$, in which time axis is added to $3 \mathrm{D}$ as the fourth dimension, is in principle impossible. X-ray computed tomography (CT) is able to provide unique information on the chemical concentration within the bulk of a material in 3D/4D. In the case of pure binary systems in which two constituent atoms are relatively apart in atomic number, X-ray CT can provide chemical concentration distributions quantitatively. However, since Xray mass absorption coefficient is obtained simply from the sum of the absorption cross sections of constituent atoms, the quantitative measurement does not apply to ternary or more complex systems such as commercial alloys.

K-edge subtraction imaging technique was originally developed for the diagnostic of neurovascular pathology with iodine-containing contrast agent ${ }^{1)}$ and later extended to lung imaging with inhaled contrast agent containing xenon gas. After a couple of monochromatic images is acquired above and below an X-ray K-edge energy, logarithmically subtracting the two images enables to enhance the contrast of any structures containing a contrast agent. Recently Justice et al. applied this technique to segment $\mathrm{ZrO}_{2}$ particles embedded in an aluminum matrix from voids. ${ }^{2)}$ Ikeda et al. have further extended this technique to realize quantitative chemical composition analysis by calibrating linear absorption coefficients, demonstrating 3D Cs concentration maps in granite. ${ }^{3)}$ They clarified that compositional resolution is 2.5 mass $\%$ at the K-edge energy of Cs located at $35.985 \mathrm{keV}$ using an imaging set-up of $20 \mu \mathrm{m}$ in spatial resolution. The present authors have also applied this technique for quantifying $3 \mathrm{D}$ chemical concentration distribution to obtain the spatial distribution of copper and its change during a solution treatment in an $\mathrm{Al}-\mathrm{Si}-\mathrm{Cu}$ alloy, providing interpretations of

\footnotetext{
${ }^{* 1}$ Corresponding author, E-mail: toda@me.tut.ac.jp

${ }^{* 2}$ Graduate Student, Toyohashi University of Technology
}

the improved mechanical properties in terms of age-hardenability and its spatial variation. ${ }^{4)}$ It has been also confirmed that the occurrence of incipient local melting and the accompanying growth of micro pores adjacent to the melt regions lead to fractures caused by these defects. However, it can be inferred that spatial resolution and reproducibility for the chemical concentration mapping have not been established to a reasonable extent yet.

In order to apply this technique more extensively to the material science and engineering, common alloying elements in commercial materials, such as $\mathrm{Fe}, \mathrm{Ni}, \mathrm{Cu}, \mathrm{Zn}$ and $\mathrm{Zr}$, which have much lower K-edge energies, should be examined with the recently improved spatial resolution level (i.e., around $1 \mu \mathrm{m}$ or less). Accuracy, detectability and reproducibility are of major concern from a practical point of view. In the present study, the multienergy imaging across $\mathrm{Cu}$ $\mathrm{K}$-edge located at $8.977 \mathrm{keV}$ has been performed to examine the above-mentioned issues.

\section{Experiments}

Aluminum with a purity of $99.99 \%$ and $\mathrm{Al}-40 \% \mathrm{Cu}$ mother alloys were used to prepare $\mathrm{Al}-\mathrm{Cu}$ pure binary alloys. The alloy was melted in ambient laboratory air, and then poured into a steel mould preheated at $473 \mathrm{~K}$. Copper concentration of the alloys were $0.5,1,3$ and 5 mass $\%$. The samples were solution heat-treated at $813 \mathrm{~K}$ for $10.8 \mathrm{ks}$ in a salt bath, quenched in iced (hereinafter called ST), and some of the materials was then artificially aged for $28.8 \mathrm{ks}$ at $453 \mathrm{~K}$ to provide a T6 temper condition. Square samples of about $200 \mu \mathrm{m}^{2}$ in cross-section were machined. A $99.99 \%$ copper thin film with a thickness of $5 \mu \mathrm{m}$ and the Al-5 mass $\% \mathrm{Cu}$ films with a thickness of $100 \mu \mathrm{m}$ were used to obtain X-ray absorption spectra near the $\mathrm{Cu}$ K-edge. $99.999 \%$ aluminum and $99.9 \%$ magnesium wires and a $99.99 \%$ titanium thin film were prepared to obtain correction coefficients for linear absorption coefficient. The thickness values of thin titanium film $(25 \mu \mathrm{m})$ and aluminum and magnesium rectangular cylinders $(200 \mu \mathrm{m})$ were determined so that X-ray transmissivity becomes about $20 \%$. 
X-ray tomography was performed using beamline BL20XU of the synchrotron radiation facility SPring-8. A monochromatic X-ray beam produced by a Si (111) monochromator was used. An image detector was positioned $3 \mathrm{~mm}$ behind the sample, making the imaging system insensitive to phase modulation. The used X-ray energies for K-edge subtraction imaging were tuned just above and below the $\mathrm{Cu}$ K-edge (i.e., 9.038 and $8.938 \mathrm{keV}$ ), respectively. The other details are available elsewhere. ${ }^{5)}$ Image slices were reconstructed and isotropic voxels with $0.5 \mu \mathrm{m}$ edges were achieved in the reconstructed slices. After acquiring a 3D image, spatial resolution was evaluated from the slopes of an edge response function (Gaussian) around pore/aluminum interfaces. Measured spatial resolution was $1.25 \mu \mathrm{m}$ on average that is close to the physical limit (twice the voxel size; $1.0 \mu \mathrm{m}$ ) for the set-up.

\section{Results and Discussion}

$\mathrm{X}$-ray attenuation caused by the photoelectric absorption of $\mathrm{Cu}$ disappears and the overall $\mathrm{X}$-ray attenuation decreases by a factor of about 7 at the $\mathrm{Cu}$ K-edge. Since the energy resolution for the beamline is $\Delta E / E \approx 10^{-4}$, where $E$ is the $\mathrm{X}$-ray energy, two consecutive tomographic images of an identical sample can be captured at two slightly different Xray energies, completely dividing the two energies. The 3D image captured at the higher energy contains information provided by Compton scattering and photoelectric absorption from all the chemical elements in a sample, while the image captured at the lower energy contains almost identical information except for the absence of photoelectric absorption by $\mathrm{Cu}$. Image registration was then performed for the two images with an accuracy of one voxel. Digital subtraction of the two images resulted in the visualization of the $\mathrm{Cu}$ distribution in the sample. The measured mass absorption coefficients, $\mu_{\mathrm{m}}^{\mathrm{E}}$, at $E$ are given as follows;

$$
\mu_{\mathrm{m}}^{\mathrm{E}}=C_{\mathrm{Cu}} \mu_{\mathrm{m}, \mathrm{Cu}}^{\mathrm{E}}+\left(1-C_{\mathrm{Cu}}\right) \mu_{\mathrm{m}, \text { others }}^{\mathrm{E}}
$$

where $\mu_{\mathrm{m}, \mathrm{Cu}}{ }^{\mathrm{E}}$ and $\mu_{\mathrm{m}, \text { others }}{ }^{\mathrm{E}}$ are the average mass absorption coefficients of $\mathrm{Cu}$ and remaining elements at $E$, respectively, and $C_{\mathrm{Cu}}$ is the mass concentration of $\mathrm{Cu}$ in the entire material. The difference between $\mu_{\mathrm{m}}{ }^{\mathrm{E}}$ for the lower and upper $E$ can be corrected using the Victoreen's equation. ${ }^{6)}$ The absorption coefficient of $\mathrm{Al}$ varies by approximately 3\% from 93 to $90 \mathrm{~cm}^{-1}$ between 8.87 and $9.07 \mathrm{keV} . C_{\mathrm{Cu}}$ can then be obtained as follows by eliminating $\mu_{\mathrm{m} \text {,others }}{ }^{\mathrm{E}}$ from eq. (1);

$$
C_{\mathrm{Cu}}=\frac{\Delta \mu \rho_{\mathrm{Cu}}}{\left(\mu_{\mathrm{Cu}}^{\text {Upper E }}-\mu_{\mathrm{Cu}}^{\text {Lower E }}\right) \rho_{\text {alloy }}}
$$

where $\Delta \mu$ is obtained for each voxel by subtraction, $\mu_{\mathrm{Cu}}{ }^{\mathrm{E}}$ is the linear absorption coefficient of $\mathrm{Cu}$ at $E$, and $\rho$ is density. Age-hardening precipitates, which appear during the aging treatment, are much smaller than the size of a voxel $(0.5 \mu \mathrm{m})$ in this study. Therefore, linear absorption coefficients measured at $9.07 \mathrm{keV}$ can be expressed by simply adding the contributions from $\alpha$-Al, $\theta^{\prime \prime}-\mathrm{Al}_{2} \mathrm{Cu}$ and $\theta^{\prime}-\mathrm{Al}_{2} \mathrm{Cu}$.

Linear absorption coefficients are corrected according to correction lines obtained with the three pure metals to ensure the accuracy of the subsequent linear absorption coefficient measurement as shown in Fig. 1. Firstly, the Ti wire of about

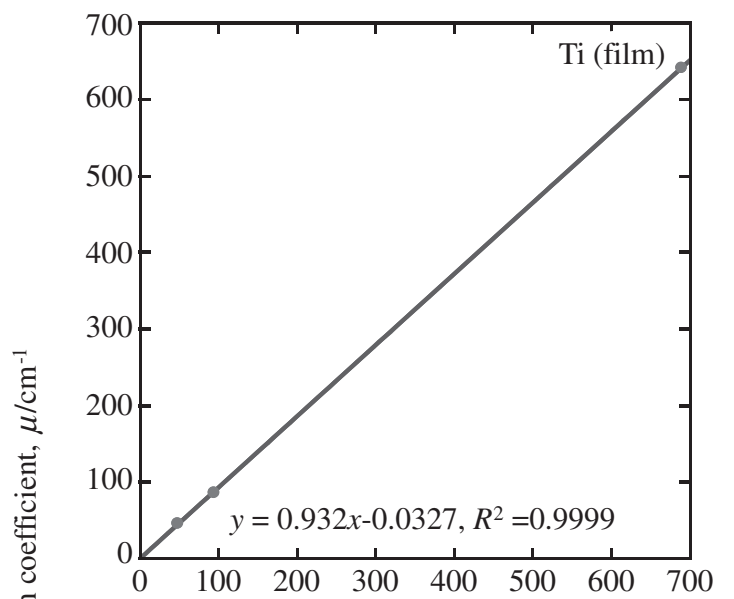

Theoretical linear absorption coefficient, $\mu^{\mathrm{T}} / \mathrm{cm}^{-1}$

(a) Sample-detector distance of $3 \mathrm{~mm}$

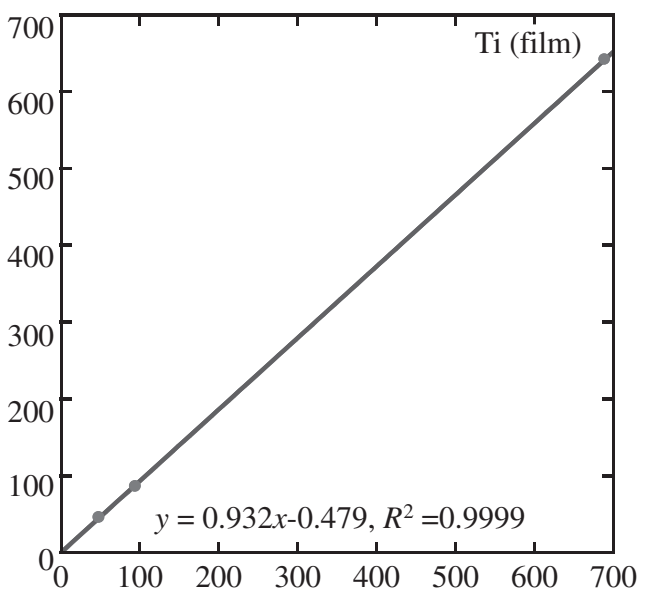

Theoretical linear absorption coefficient, $\mu^{\mathrm{T}} / \mathrm{cm}^{-1}$

(b) Sample-detector distance of $20 \mathrm{~mm}$

Fig. 1 Relationships between measured and theoretical linear absorption coefficient values for three pure metals, representing the correlation coefficient of 0.932 for the two sample-detector distances at $9.038 \mathrm{keV}$.

$50 \mu \mathrm{m}$ in diameter was used for this correction. There were significant deviations from Gaussian forms in the theoretical $\mathrm{X}$-ray linear absorption coefficient profiles of titanium, due to a small wire diameter (i.e., $50 \mu \mathrm{m}$ ). The plots for the three metals showed out of alignment in a calibration chart. Therefore the titanium film was then used and perfect alignment was obtained as shown in Fig. 1. The correction and correlation coefficients for the sample detector distances of 3 and $20 \mathrm{~mm}$ are 0.932 and 0.9999 , respectively at the Xray energy of $9.038 \mathrm{keV}$. Tsuchiyama, et al. has also reported a similar discrepancy between measured and theoretical linear absorption coefficient values in the beam line BL20B2 of the SPring-8. ${ }^{7)}$ The value reported by them is $0.887 \pm$ 0.0039 and they claimed deviation from the line with the increase in linear absorption coefficient, suggesting that the evaluation of correction coefficients is indispensable for each beam line.

Absorption spectra were corrected in the 8.87 to $9.07 \mathrm{keV}$ photon energy range around the $\mathrm{Cu}$ K-edge as shown in Fig. 2. The monochromatized radiation was continuously monitored with ionization chambers. An as-cast $\mathrm{Al}-5 \% \mathrm{Cu}$ 


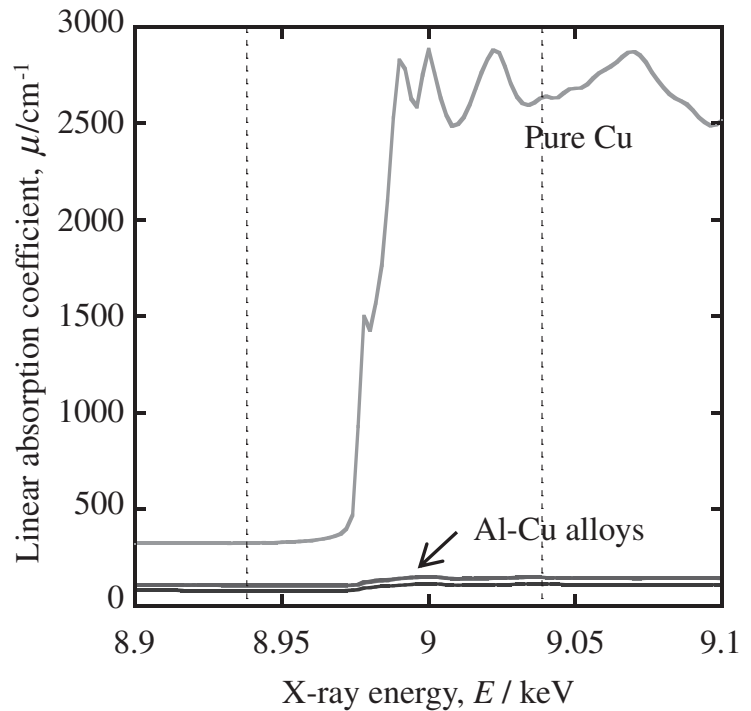

(a) Absorption spectra

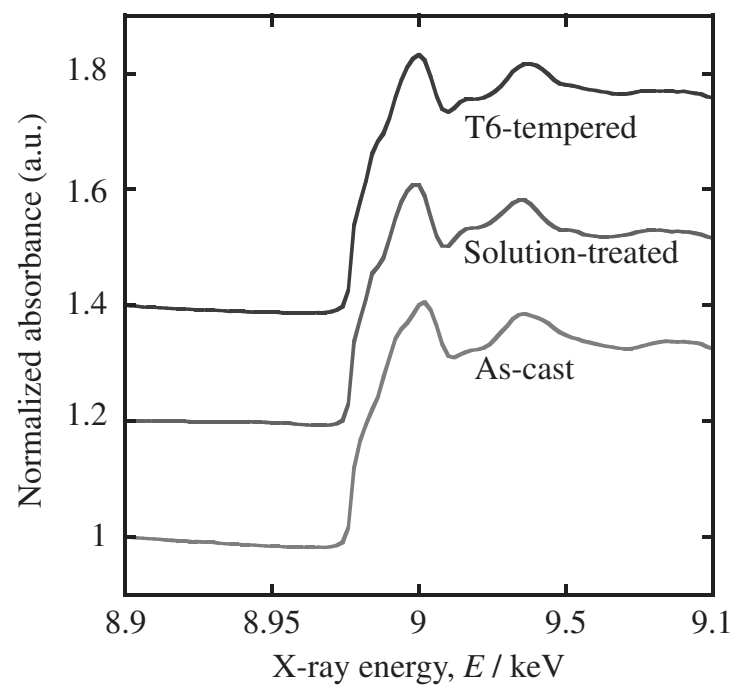

(b) Magnified spectra of the Al-Cu alloys

Fig. 2 Absorption spectra measured around the $\mathrm{Cu}$ K-edge for a pure copper and three $\mathrm{Al}-5 \% \mathrm{Cu}$ alloys tempered to different conditions. The spectra for the latter alloys are magnified in (b).

alloy and those tempered to ST and T6 conditions were examined in addition to the pure copper film as shown in Fig. 2(a). Although slight differences in near-edge features can be seen as shown in the magnified plots shown in Fig. 2(b) due probably to the difference in chemical bonding states between copper and aluminum, accurate chemical composition analysis is enabled by adopting 8.938 and $9.038 \mathrm{keV}$ as lower and upper energies without being affected by the near-edge features.

Examples of $\mathrm{Cu}$ concentration mapping after digital subtraction are shown in Fig. 3, representing the variation in $\mathrm{Cu}$ distribution during ST. Comparing with $\mathrm{Cu}$ concentration maps on identical cross-sections that have been obtained with the SEM-EDX technique, the present technique exhibited a considerable advantage in the amount of statistical noise. Measured total $\mathrm{Cu}$ concentration values agreed well between the two techniques in the $\mathrm{Cu}$ concen-

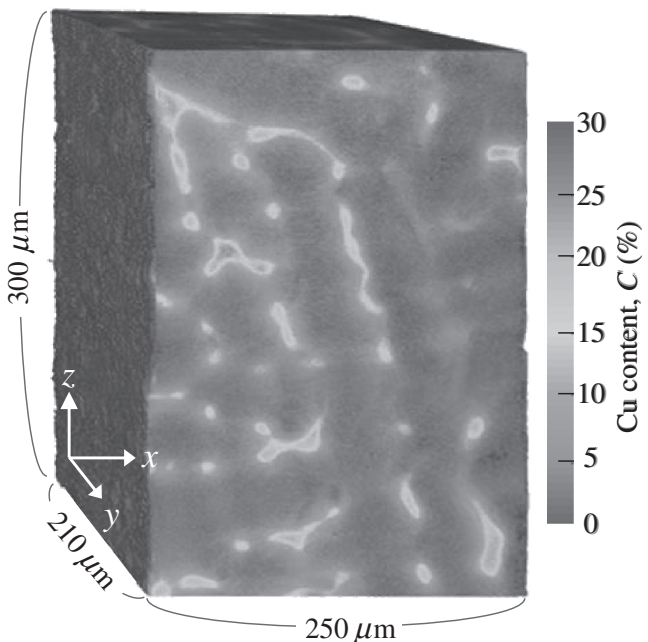

(a) As-cast material

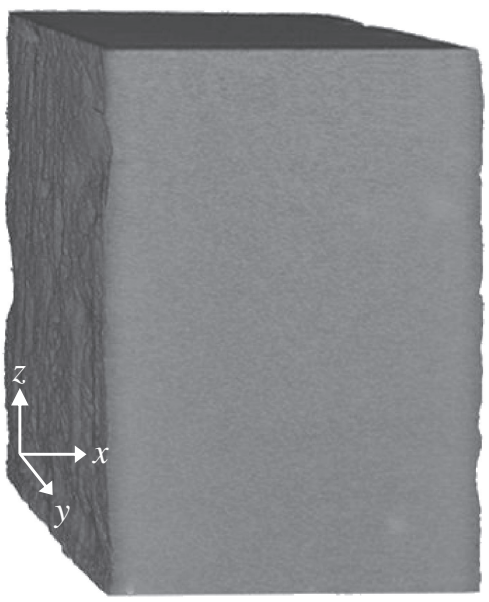

(b) Solution-treated material

Fig. $3 \mathrm{Cu}$ concentration maps shown on sample surface before and after the solution treatment for (a) an as-cast and (b) solution-treated alloys.

tration range of 0.5 to 5 mass $\%$. Eutectic microstructure formed during solidification apparently tends to disappear during the ST at the high temperature for the relatively long time in Fig. 3. Since it has been reported that the $\mathrm{Al}-\mathrm{Cu}$ binary eutectic reaction starts at $817.3 \mathrm{~K},{ }^{4)}$ the ST temperature of $813 \mathrm{~K}$ would be close to or exceed an upper limit for the Al-Cu alloy. Nevertheless, slight segregation is yet observed in Fig. 3(b) yet. In order to evaluate the remaining local segregation and its spatial variation, ten spherical regions with diameter of $20 \mu \mathrm{m}$ were chosen as shown in Fig. 4(a). The distribution profiles of the $\mathrm{Cu}$ concentration in the ten regions are shown in Fig. 4(b). The $\mathrm{Cu}$ concentration profile in region number 10 appears to be right-skewed, compared with the other nine almost symmetrical distributions, suggesting the existence of $\mathrm{Cu}$-rich intermetallic particles exist in this region. The differences in width and peak height of the ten distributions appear to be more significant than expected. In general, fracture path is more or less tortuous even in the case of an ideally homogenized model material. Results obtained from Figs. 3 and 4 suggest that microstructural inhomogeneity is hard to be eliminated even with the seemingly complete heat treatment. 


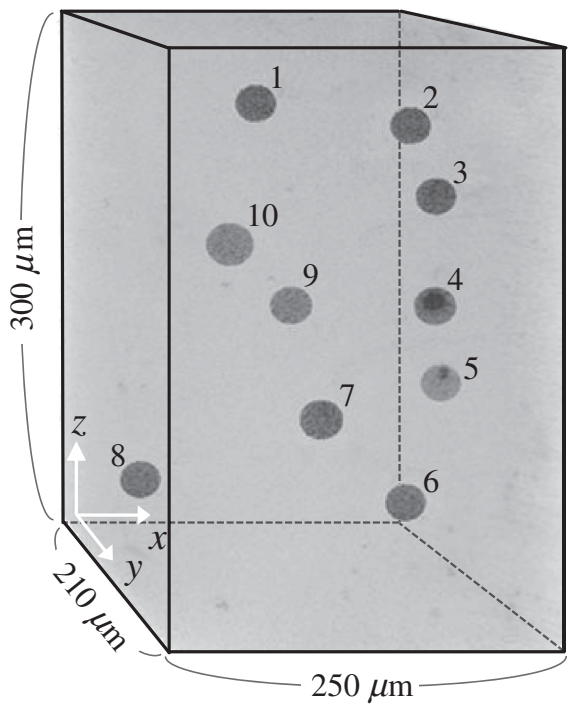

(a) Ten regions sampled

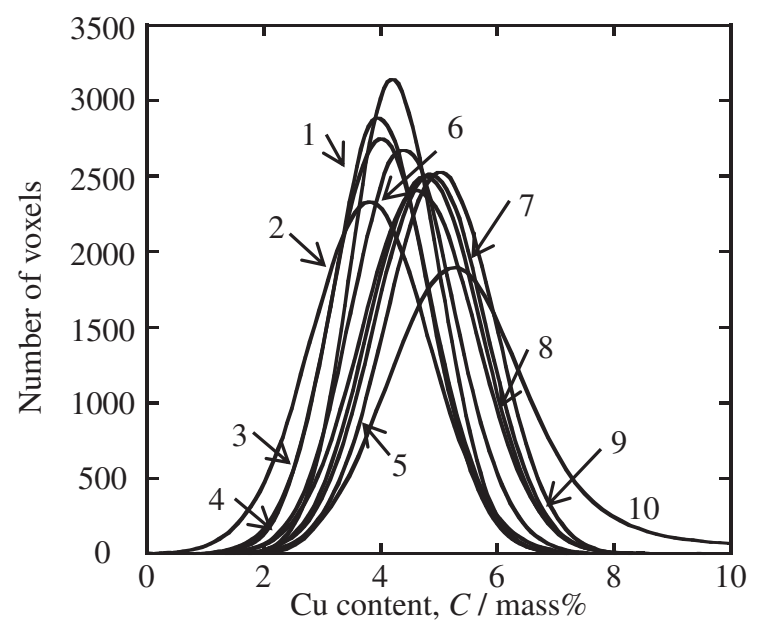

(b) $\mathrm{Cu}$ concentration profile

Fig. 4 The distribution profiles of $\mathrm{Cu}$ concentration in ten spherical regions shown in (a). The regions with diameter of $20 \mu \mathrm{m}$ have been randomly sampled in the as-solution-treated Al-5\% Cu alloy shown in Fig. 3(b).

Repeatability of the measurement has been evaluated to reveal the inherent precision of the K-edge subtraction imaging technique. Three sets of the images of the identical as-cast sample were captured consecutively at the lower and upper energies without changing sample location. Total $\mathrm{Cu}$ concentrations for the whole field of view were 5.28, 5.09 and $5.23 \%$ that are within approximately $4 \%$ in variation. Although there is some possibility of $\mathrm{Cu}$ flow from the field of view for imaging to neighboring regions during the heat treatment, total $\mathrm{Cu}$ concentrations in the field of view was also compared. It varied from 5.09 to 4.89 mass $\%$ during the ST, which also corresponds to approximately $4 \%$ variation.
In the similar tracking of an identical region of an Al-6Si$4 \mathrm{Cu}$ alloy in a companion paper, ${ }^{4)}$ although there is also some possibility of change in total $\mathrm{Cu}$ concentration in the field of view, total $\mathrm{Cu}$ concentrations varied at $807 \mathrm{~K}$ as $4.11 \mathrm{mass} \%$ at $0 \mathrm{ks}, 4.26 \mathrm{mass} \%$ at $0.9 \mathrm{ks}, 4.35 \mathrm{mass} \%$ at $1.8 \mathrm{ks}, 4.23$ mass $\%$ at $3.6 \mathrm{ks}, 4.30$ mass $\%$ at $7.2 \mathrm{ks}$ and 4.25 mass $\%$ at $10.8 \mathrm{ks}$. ${ }^{4)}$ This also corresponds to about $4 \%$ variation between the neighboring data at maximum. It can therefore be concluded that the repeatability of the K-edge subtraction imaging is about $4 \%$ for $\mathrm{Cu}$ with the present set-up used.

\section{Summary}

The dual-energy K-edge subtraction imaging technique has been employed to demonstrate the $3 \mathrm{D} / 4 \mathrm{D}$ (i.e., $3 \mathrm{D}+$ time axis) distribution of copper and its changes during the ST. Various evaluations necessary for realizing the $3 \mathrm{D} / 4 \mathrm{D}$ chemical concentration measurements have been performed, such as the calibration of linear absorption coefficient, the evaluation of near-edge features for the aluminum alloys and that for repeatability. It has been clarified that complete homogenization cannot be obtained even with the ST at the high temperature for the relatively long time, representing inherent microstructural inhomogeneity in real metallic materials.

\section{Acknowledgements}

The synchrotron radiation experiments were performed with the approval of JASRI through proposal numbers 2006B1239, 2007A1431 and 2008A1104. One of the authors (HT) is also grateful for the support of the Light Metal Educational Foundation.

\section{REFERENCES}

1) E. Rubenstein, R. Hofstadter, H. D. Zeman, A. C. Thompson, J. N. Otis, G. S. Brown, J. C. Giacomini, H. J. Gordon, R. S. Kernoff, D. C. Harrison and W. Thomlinson: Proc. Natl. Acad. Sci. USA 83 (1986) pp. 9724-9728.

2) I. Justice, B. Derby, G. Davis, P. Anderson and J. Elliott: Scr. Mater. 48 (2003) 1259-1264.

3) S. Ikeda, T. Nakano, A. Tsuchiyama, K. Uesugi, Y. Suzuki, K. Nakamura, Y. Nakashima and H. Yoshida: Am. Mineral. 89 (2004) 1304-1312.

4) H. Toda, T. Nishimura, K. Uesugi, Y. Suzuki and M. Kobayashi: Acta Mater. 58 (2010) 2014-2025.

5) H. Toda, S. Yamamoto, M. Kobayashi and K. Uesugi: Acta Mater. 56 (2008) 6027-6039.

6) C. H. MacGillavry and G. D. Rieck (Eds.): International Tables for $X$-Ray Crystallography, Vol. III. Physical and Chemical Tables, (The Kynoch Press, Birmingham, England, 1962) p. 161.

7) A. Tsuchiyama, K. Uesugi, T. Nakano and S. Ikeda: Am. Mineral. 90 (2005) 132-142. 